\title{
Therapeutic surgery in failures of medical treatment for fungal keratitis
}

\author{
RICHARD K. FORSTER AND GERBERT REBELL \\ From the Bascom Palmer Eye Institute, Department of Ophthalmology, University of Miami, School of Medicine, Miami, \\ Florida
}

Before the use of Natamycin (Pimaricin), i 1 out of 20 Fusarium ulcers diagnosed at the Bascom Palmer Eye Institute and reported by Jones, Sexton, and Rebell (rg69), necessitated therapeutic surgery because of failures of medical treatment. Despite elimination of active fungal disease in 13 out of 15 keratoplasties, Sanders (1970) found that useful vision was retained in only three cases.

Since Natamycin became available Polack, Kaufman, and Newmark (1971) have reported 22 therapeutic surgical procedures in 33 fungal ulcers, including six in medical failures.

These reports prompted us to examine the culture and histopathological results in nine medical failures out of 53 cases that have been treated during the past $4 \frac{1}{2}$ years; and to examine the visual results in patients treated with Natamycin, but in whom therapeutic surgery was necessary.

Address for reprints: Richard K. Forster MD, Department of Ophthalmology, University of Miami, School of Medicine. P.O. Box, 875, Biscayne Annex, Miami, Florida 33152

Supported in part by: Public Health Services Grant No. 5 RO1 E Y00674-02, from the National Eye Institute; Fight for Sight Grant No. G-457; United Health Foundation of Dade County Grant: The Florida Lions Eye Bank; and The Flournory and Mae Knight Clark Research Fund

\section{Material and methods}

\section{PATIENTS}

During the past $4 \frac{1}{2}$ years ro out of 53 fungal ulcers proved by culture necessitated surgery. These included six cases in which penetrating keratoplasty was necessary because of impending perforation or treatment failure; one patient who presented with a perforated cornea and underwent keratoplasty; one patient in whom the ulcer remained superficial, but who failed to respond to medical treatment so that a conjunctival flap was necessary; and an enucleation in a case in which treatment failed. A final ulcer caused by a yeast had only intermittent Natamycin therapy, no culture of the corneal fragments at surgery, and no follow-up, and was therefore not included in this survey.

\section{MEDICAL TREATMENT}

Eight out of nine patients had one or more days of Natamycin (Pimaricin) 5 per cent suspension, before therapeutic surgery. Six patients were treated for at least 7 days, and two patients were treated for only $I$ and 3 days before keratoplasty.

Table Culture and histopathological results in nine fungal keratitis medical failures

\begin{tabular}{|c|c|c|c|c|c|c|c|}
\hline $\begin{array}{l}\text { Case } \\
\text { No. }\end{array}$ & Isolate & $\begin{array}{l}\text { Treated with } \\
\text { Natamycin } \\
\text { (days) }\end{array}$ & Surgery* & Cultures & Histopathology & $\begin{array}{l}\text { Final } \\
\text { vision }\end{array}$ & $\begin{array}{l}\text { Follow-up } \\
\text { (months) }\end{array}$ \\
\hline $\mathbf{I}$ & $\begin{array}{l}\text { Curvularia } \\
\text { senegalensis }\end{array}$ & o & PK & + & + & $20 / 40+$ & 40 \\
\hline 2 & Fusarium solani & 35 & PK & - & - & $20 / 70$ & 37 \\
\hline 3 & Fusarium episphaeria & 30 & $\begin{array}{l}\text { Conjunctival } \\
\text { flap }\end{array}$ & - & + & $\mathrm{I} / 200$ & 31 \\
\hline 4 & Fusarium solani & 7 & PK & + & + & NI & $\begin{array}{l}\text { Lost to } \\
\text { follow-up }\end{array}$ \\
\hline 5 & Fusarium solani & 14 & Enucleation & ND & + & NPL & - \\
\hline 6 & Volutina sp. & I & PK & + & - & $\mathrm{CF}$ at $0.9 \mathrm{~m}$ & 18 \\
\hline 7 & Acremonium potronii & 30 & PK & + & + & $20 / 60$ & 8 \\
\hline 8 & $\begin{array}{l}\text { Fusarium, probably } \\
\text { moniliforme }\end{array}$ & 3 & PK & + & + & $20 / 20$ & I5 \\
\hline 9 & Fusarium solani & I I & PK & - & + & $20 / 50$ & 7 \\
\hline
\end{tabular}

* PK = penetrating keratoplasty. ND = not done. $\mathrm{CF}=$ counting fingers. $\mathrm{NI}=$ not indicated.

NPL $=$ No perception of light. 


\section{LABORATORY DIAGNOSIS AND CULTURES}

At the time of surgery corneal fragments were cultured on Sabouraud agar, blood agar at $26^{\circ} \mathrm{C}$, or brain-heart infusion liquid (BHI). Corneal buttons were halved, divided, and placed in the medium, the second half being placed in ro per cent formaldehyde for histopathological examination.

\section{HISTOPATHOLOGY}

Corneal fragments, halved corneal buttons, and in one case an enucleated globe were stained by haematoxylin and eosin (H and. E), Gomori's methenamine silver nitrate technique (GMS), and periodic acid-Schiff (PAS) reaction.

\section{Results}

Four cases received 7 or more days of Natamycin therapy before being subjected to penetrating keratoplasty (see Table, Cases 2, 4, 7, and 9). These were all considered to be failures of treatment, although Case 7 had a deep corneal abscess with $20 / 30$ vision in which a small $5 \mathrm{~mm}$ keratoplasty was performed for diagnostic as well as therapeutic purposes. Cultures were positive in two cases, and negative in two cases. One culture negative case had hyphae demonstrated pathologically (Case 9). In the other culture negative case no hyphae were seen on pathological examination (Case 2). In the two culture positive cases (Cases 4 and 7) fungal elements were seen pathologically (Fig. I).
In two cases (Cases 6 and 8) the cornea perforated after only $I$ and 3 days of Natamycin treatment, and necessitated therapeutic penetrating keratoplasty, combined with a lens extraction in Case 8. Both were culture positive and hyphae were seen pathologically in Case 8, but not in Case 6.

Case I was referred with a perforated cornea after $2 \frac{1}{2}$ months of non-specific treatment which included steroids and antibiotics. Cultures were positive for Curvularia senegalensis and hyphae were seen on histopathological examination.

Progressive superficial ulceration was unaltered by 30 days of Natamycin therapy in Case 3, from which Fusarium episphaeria had been isolated. A superficial keratectomy with a total conjunctival flap was performed. Cultures from corneal fragments were negative, but degenerate, apparently non-viable fungal elements were seen in abundance pathologically (Figs 2 and 3 ).

Case 5 presented as a ring ulcer with central progression due to Fusarium solani. After I4 days of Natamycin therapy the ulcer had progressed to perforation, apparent endophthalmitis, and severe pain necessitating an enucleation. Although cultures were not obtained at surgery, histopathological studies demonstrated fungal elements.

The eight therapeutic procedures were apparently successful in eliminating the active keratitis, and useful vision was obtained in five out of six penetrating keratoplasties followed-up for 7 to 40 months (Table).

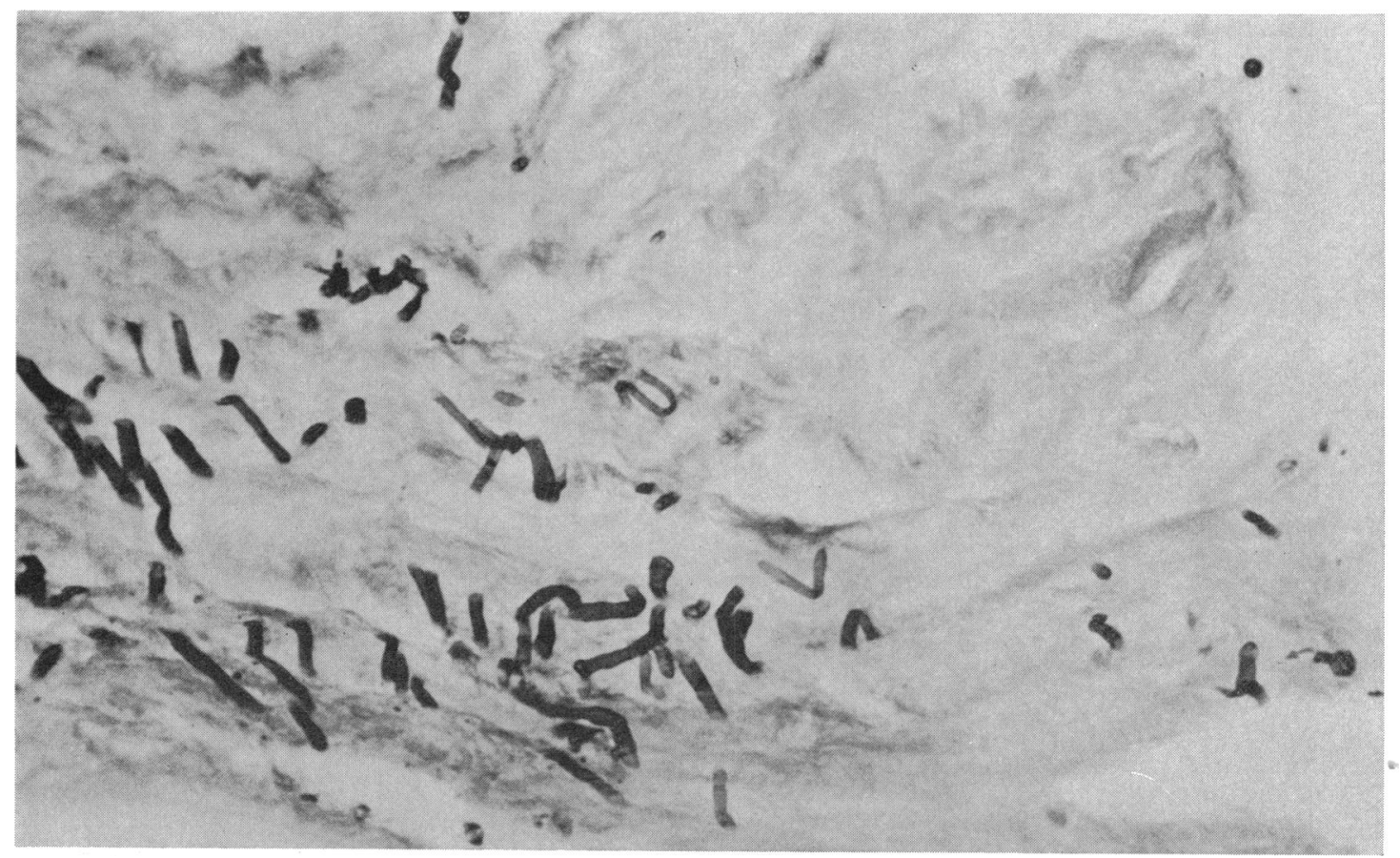




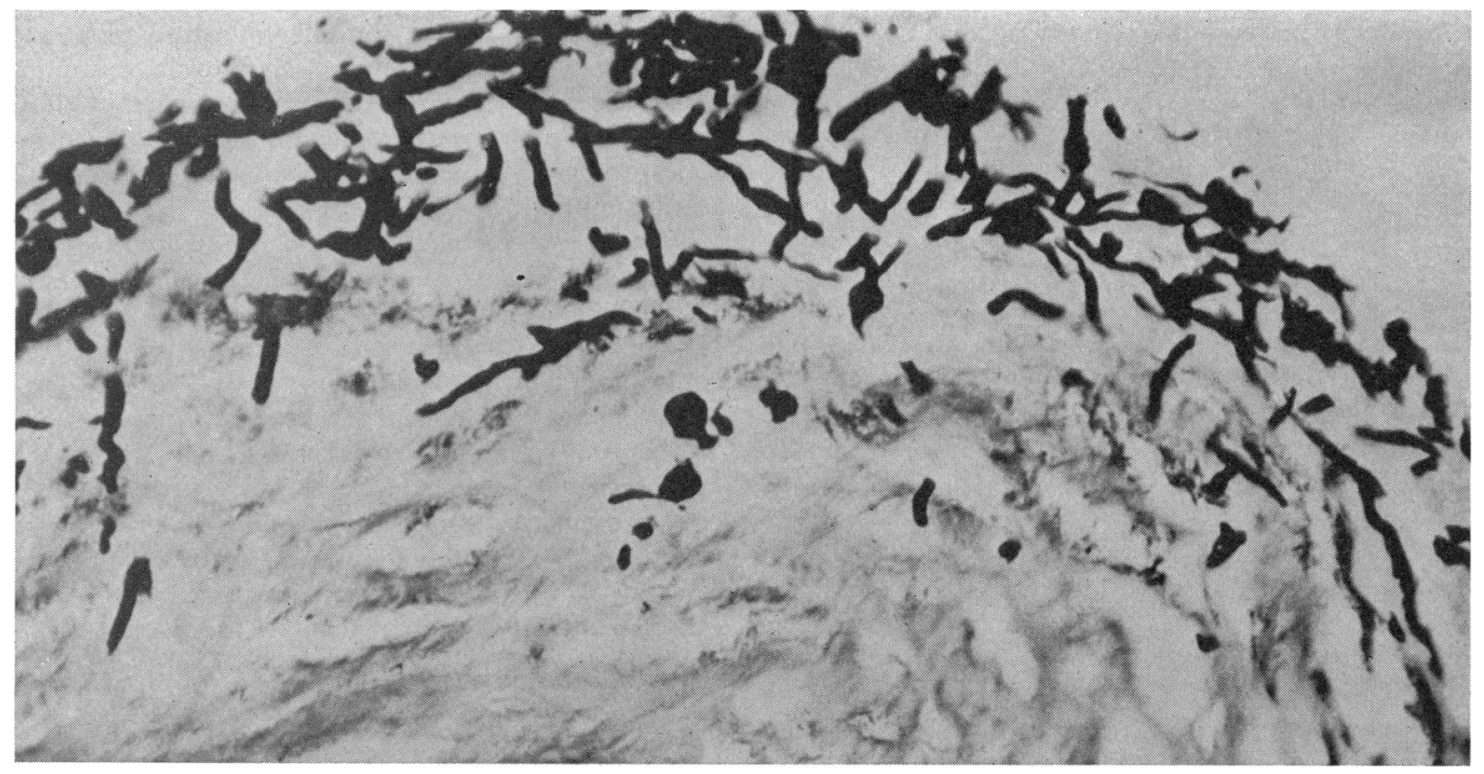

FI G. 2 Non-viable hyphal fragments. Case 3 (GMS)

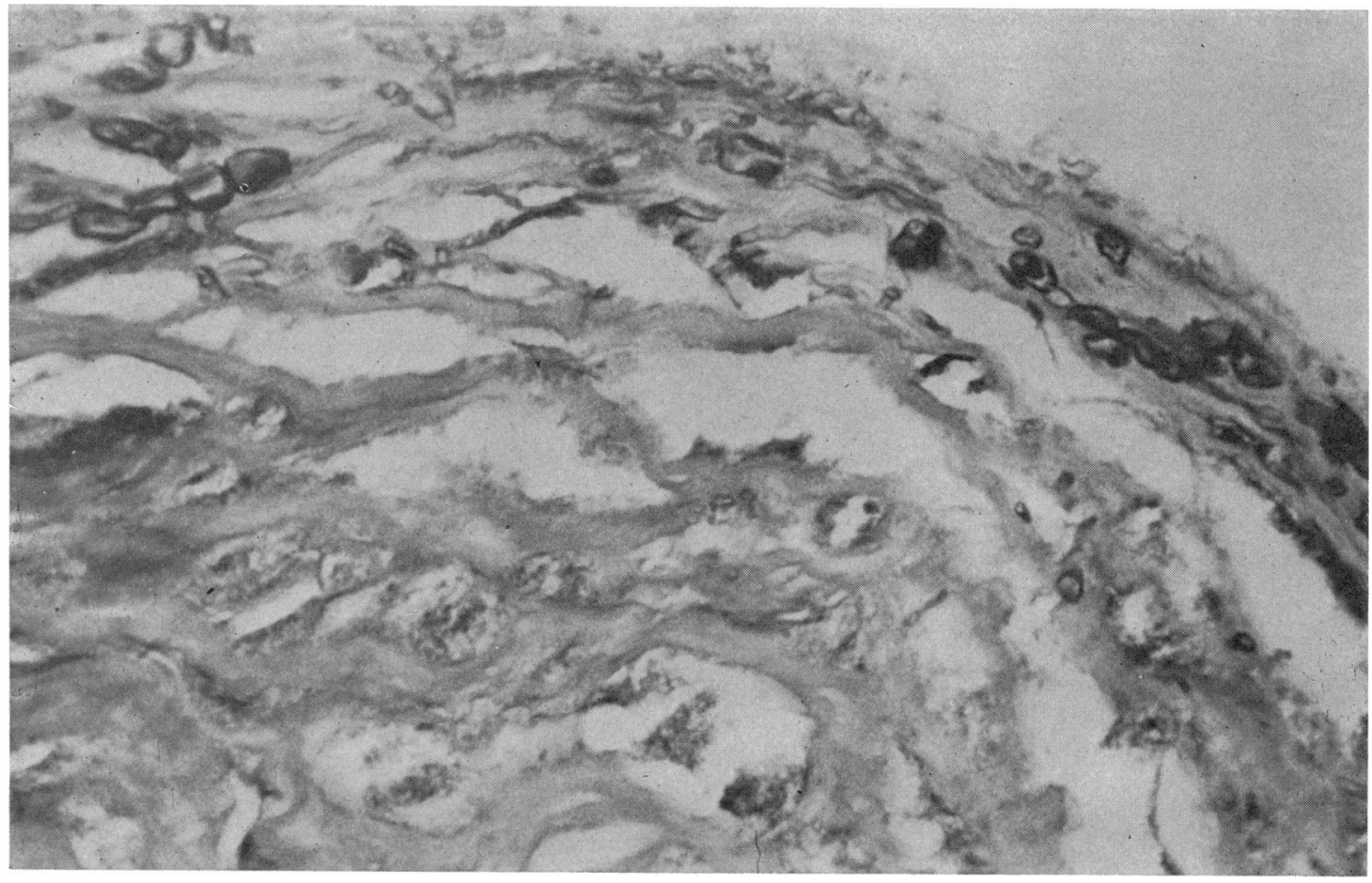

FI G. 3 Degenerated hyphae. Case 3 (PAS) 
The graft performed after only one day of Natamycin treatment, in Case 6, became cloudy, but maintained a visual acuity of counting fingers at $0.9 \mathrm{~m}$ and would be amenable to optical surgery later if required.

\section{Discussion}

Anderson and Chick (1963) noted altered hyphae pathologically in culture negative corneal fragments after 3 weeks of Amphotericin treatment. Cases 3 and 9, in which the ulcer was due to Fusarium episphaeria and $F$. solani, behaved in a similar manner. They were treated with Natamycin for 30 and I I days respectively, and at the time of keratectomy and keratoplasty, had negative cultures from corneal fragments, but hyphae were demonstrated pathologically. The fungal elements in Case 3 remained superficial and appeared altered or degenerate. This finding suggests that the Natamycin treatment rendered the fungi non-viable, but that other factors contributed to progression or perforation of the ulcers. An additional case (Case 2) of $F$. solani keratitis showed an initial response to Natamycin, then after 2 weeks developed a recur- rent hypopyon and threatened perforation. Both cultures and histopathological studies were negative from the keratoplasty specimen. Presumably Natamycin eliminated the infection and hyphal elements disappeared or were not recognized (Fig. 4). A similar observation was made by Kaufman and Wood (1965) in a case of Fusarium keratitis treated with thiomersal.

Before the use of Natamycin, although therapeutic keratoplasty eliminated infection, visual results were discouraging.

Polack and others (1971) reported four keratoplasties which had failed after medical therapy in cases of Cephalosporium and Fusarium keratitis. Although the number of days of medical therapy was not indicated, all obtained $20 / 60$ or better vision. In one case, keratoplasty was preceded by a conjunctival flap operation.

Three cases treated for 7 days or more with Natamycin that subsequently necessitated keratoplasty have likewise suggested that the prognosis was better if the fungus can be rendered non-viable before keratoplasty. In the last four cases in which it appeared

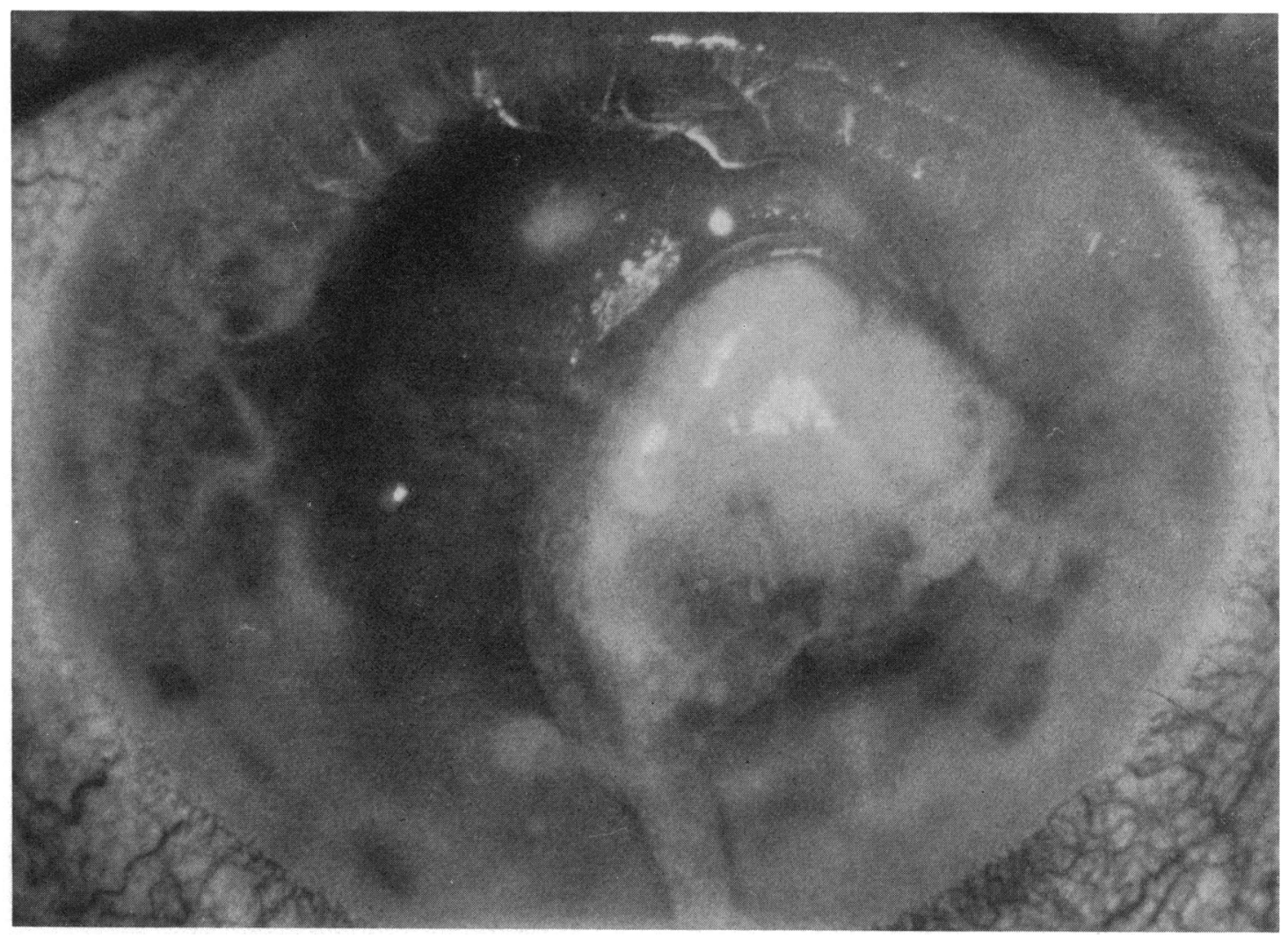

F IG. 4 (Case 2) (a) Appearance of ulcer at diagnosis

4 (b) After 2 days of Natamycin therapy (overleaf)

$4(c)$ Impending perforation after 2 weeks of therapy (overleaf) 

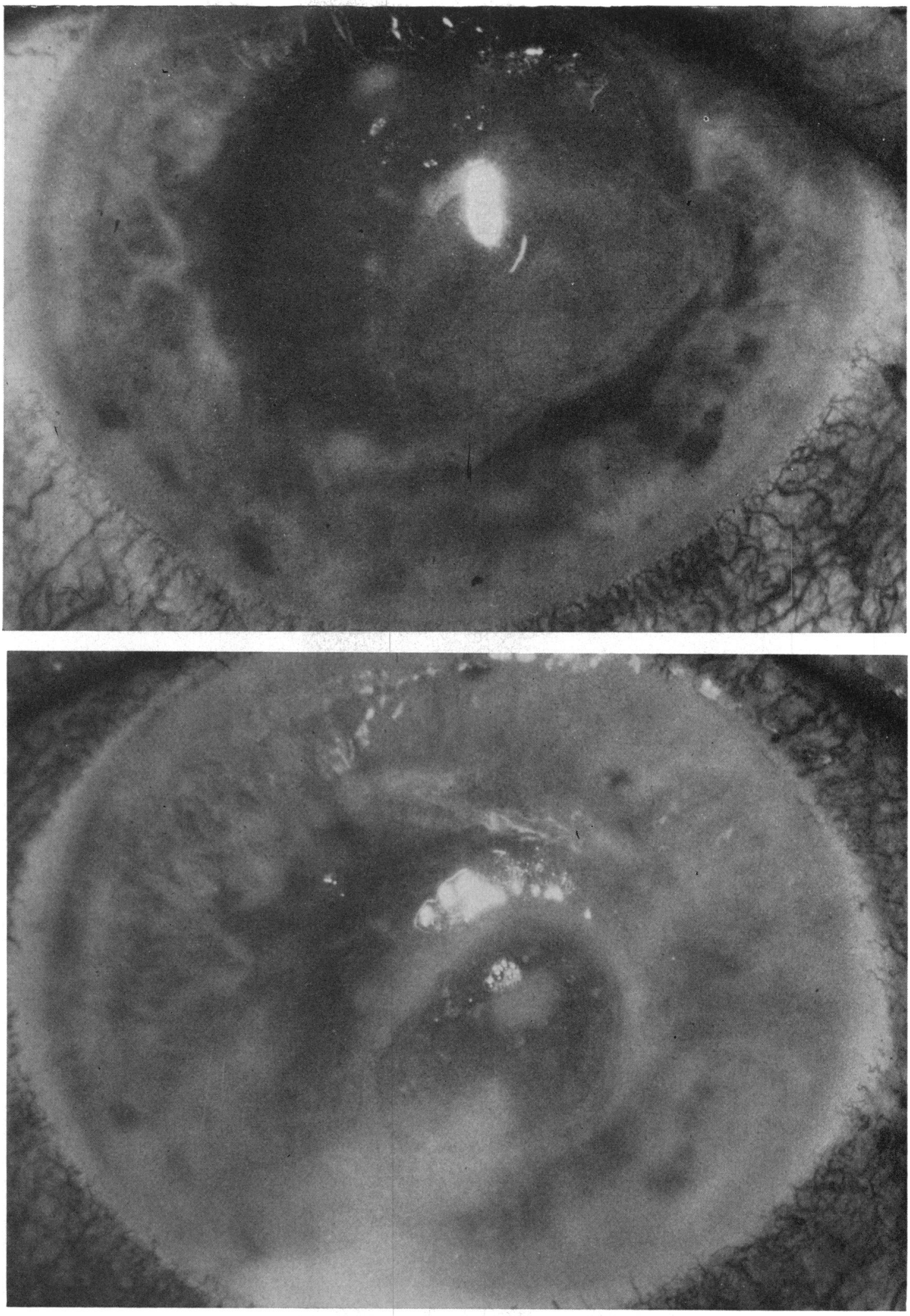
keratoplasty would be necessary, an attempt was made to treat the patients as long as reasonable before surgery, rather than to operate at once when surgery seemed inevitable. Several days of antifungal treatment in a case of impending perforation may alter or eliminate the fungi and improve the visual prognosis.

Despite 30 days of Natamycin treatment, both cultures for Acremonium potronii and histopathological studies were positive at the time of keratoplasty in Case 7. A deep stromal abscess without ulceration developed 8 months after surgical repair of a corneal laceration at which time Acremonium potronii was initially cultured. Forster, Rebell, and Styles (1975) suggest that because of poor penetration, Natamycin did not affect these deep fungal organisms. The tendency for fungi to grow deeply into the corneal stroma has accounted for poor results of therapeutic lamellar keratoplasty in advanced cases of fungal keratitis, as reported by Naumann, Green, and Zimmerman
(1967), Salceda, Nievera, and Abendaño (1969), and Singh and Malik (1972).

\section{Summary}

Medical treatment failure necessitated surgery in nine cases of fungal keratitis. Therapeutic surgery eliminated fungal infection in seven cases, and useful vision was retained in five out of six penetrating keratoplasties. In three cases Natamycin (Pimaricin) therapy rendered fungi non-viable, but two were demonstrable by histopathology. These results suggest that antifungal treatment should be applied for as long as possible before therapeutic surgery in order to improve the final visual outcome.

The authors would like to thank Manuel Solis and Blanca Montero of the Florida Lion's Eye Bank for the histopathological preparations; and Fernando Gonzalez RSP, FBPA of the Photography Department for the photomicrographs.

\section{References}

ANDERSON, B., and CHICK, E. W. (1963) Sth. med. F., 56, 270 FORSTER, R. K., REBell, G., and stiles, w. (1975) Amer. J. Ophthal., 79, 26 JONES, D. B., SEXTON, R., and Rebell, G. (1969) Trans. ophthal. Soc. U.K., 89, 78 I KaUfMan, H. E., and WOOD, R. M. (1965) Amer. F. Ophthal., 59, 993 NAUMANN, G., GREEN, W. R., and ZIMMERMAN, L. E. (I967) Ibid., 64, 668 polack, F. M., KaUfman, h. E., and newmark, e. (I97 I) Arch. Ophthal. (Chicago), 85, 410 Salceda, s. R., Nievera, L-F., and Abendaño, R. (1969) Philipp. F. Ophthal. Otolaryng., x, 3 I SANDERs, N. (1970) Amer. F. Ophthal., 70, 24 singh, G., and MALIK, s. R. K. (1972) Brit. F. Ophthal., 56, 41 